\title{
Avaliação laboratorial do tipo e teor de ligante e da granulometria na deformação permanente de misturas asfálticas
}

\author{
Pedro Orlando Borges de Almeida $\mathrm{Jr}^{1}$, Fernando Dekeper Boeira², Luciano Pivoto Specht ${ }^{3}$, \\ Tatiana Cureau Cervo ${ }^{4}$, Deividi da Silva Pereira ${ }^{5}$, Roberta Centofante ${ }^{6}$, \\ Valdir Barboza Jr ${ }^{7}$, Carlos Correia e Silva ${ }^{8}$
}

1Universidade Federal de Santa Maria, Santa Maria, RS, Brasil, engcivilpedro@hotmail.com

2Universidade Federal de Santa Maria, Santa Maria, RS, Brasil, fernando.d.boeira@gmail.com

3Universidade Federal de Santa Maria, Santa Maria, RS, Brasil, luspecht@ufsm.br

${ }^{4}$ Universidade Federal de Santa Maria, Santa Maria, RS, Brasil, cervo.tatiana@gmail.com

${ }^{5}$ Universidade Federal de Santa Maria, Santa Maria, RS, Brasil, dsp@ufsm.br

${ }^{6}$ Universidade Federal de Santa Maria, Santa Maria, RS, Brasil, robertacentofante@yahoo.com.br

7Universidade Federal de Santa Maria, Santa Maria, RS, Brasil, valdircrdc@gmail.com

8Universidade Federal do Rio de Janeiro, Rio de Janeiro, RJ, Brasil, cafilipe.correia@gmail.com

\section{Recebido:}

18 de junho de 2017

Aceito para publicação:

31 de outubro de 2017

Publicado:

31 de agosto de 2018

Editor de área:

Kamilla Vasconcelos

\section{Palavras-chaves:}

Deformação Permanente,

Ligante Asfáltico,

Método Bailey,

Flow number.

\section{Keywords:}

Permanente Deformation,

Asphalt Binder,

Bailey Method,

Flow Number.

DOI:10.14295/transportes.v26i2.1407

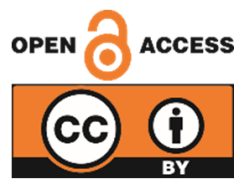

\begin{abstract}
RESUMO
Este trabalho avaliou a influência na deformação permanente do tipo e teor de ligante asfáltico e da granulometria quanto ao método Bailey, Faixa de Agregado Dominante (FAD) e faixas granulométricas $\mathrm{B}$ e $\mathrm{C}$ por meio do ensaio uniaxial de carga repetida. Para isso utilizaram-se três ligantes asfálticos, 50/70, AMP 60/85 e o Highly Modified Asphalt (HiMA), quatro granulometrias, sendo duas Faixa B e duas $C$, e dois métodos de dosagem, Superpave e Marshall, totalizando 24 misturas asfálticas. Os resultados indicaram que as modificações no tipo e no teor dos ligantes asfálticos foram mais influentes na deformação permanente do que a granulometria das misturas, inclusive encontrou-se boa correlação entre a reologia dos ligantes e os Flow Numbers (FNs) obtidos. O método Bailey apresentou-se mais efetivo em conferir ganho de resistência comparado ao método FAD e a utilização da granulometria faixa $B$ não resultou em um melhor comportamento comparado a uma granulometria faixa $\mathrm{C}$.
\end{abstract}

\section{ABSTRACT}

This paper evaluated the influence on permanent deformation of the type and content of asphalt binder and aggregate gradation as regards the Bailey method, the Dominant Aggregate Size Range (DASR) and grain size ranges $B$ and $C$ using the repeated load uniaxial test. Three asphalt binders were used, CAP 50/70, AMP 60/85, and Highly Modified Asphalt (HiMA), four aggregate size distributions, two ranges $B$ and two ranges $C$, and two dosing methods, Superpave and Marshall, totaling 24 asphalt mixtures. The results indicated that changes in the type and content of the asphalt binders were more influential on permanent deformation than the aggregate gradation of the asphalt mixtures, and a good correlation was found between the rheology of the binders and the Flow Numbers (FNs) obtained. The Bailey method was more effective at conferring resistance gain compared to the DASR method and the use of a range $B$ aggregate gradation did not result in a better behavior compared to a range $C$ aggregate gradation.

\section{INTRODUÇÃO}

0 avançado estado de degradação dos pavimentos de concreto asfáltico no Brasil decorre do crescimento do número de veículos, das cargas por eixo e das pressões dos pneus que tornam o tráfego mais severo e promovem defeitos precoces no revestimento, em especial, à deformação permanente (Alavi et al., 
2011; Zhang et al., 2013; Bastos, 2016; Kutay et al., 2017). Paralelamente, os projetos de misturas asfálticas ainda são baseados nos ensaios básicos de ligantes asfálticos requeridos pela especificação brasileira (resolução n 19 de 2005 da Agência Nacional do Petróleo), em uma seleção granulométrica por tentativa e erro através de faixas da norma DNIT 031 (2006), e sem um estudo relativo ao dano, o que pode resultar em um material não efetivo em termos mecânicos.

Esse sistema funcionou relativamente bem no passado, mas à medida que avançamos com as demandas atuais decorrentes de um tráfego mais severo, novas abordagens são fundamentais para o bom desempenho do concreto asfáltico. Dentre estas abordagens, está a influência das propriedades reológicas, como, por exemplo uma especificação por desempenho, e dos diferentes tipos e teores de ligante asfáltico, e de formas racionais e sistemáticas de seleção e avaliação granulométrica no comportamento de misturas asfálticas ao dano para mitigar o surgimento de defeitos e originar revestimentos mais duráveis (Adorjányi e Füleki, 2013; Ferreira et al., 2015).

As misturas asfálticas herdam as características viscoelásticas e termosusceptíveis dos ligantes asfálticos, que dependendo do tipo e teor apresentam-se mais ou menos susceptíveis à variação de temperatura, frequência e do tempo de aplicação de carga (Specht et al., 2017), e consequentemente, de apresentar à deformação permanente em altas temperaturas.

A modificação dos ligantes asfálticos melhora as características reológicas do material, aumentando sua consistência e reduzindo a susceptibilidade nas temperaturas extremas; por isso, muitos estudos desenvolvidos relacionam a reologia do ligante com o comportamento à deformação permanente (Mothé, 2009; Domingos, 2011; Melo, 2014; Domingos e Faxina, 2015; Nascimento et al., 2015; Domingos et al., 2017). Os ligantes de maior viscosidade, como os modificados por polímeros, apresentam maior resistência à deformação permanente (Valkering et al., 1990; Corté et al., 1994; Onofre et al., 2013; Santagata et al., 2015). Já os ligantes asfálticos de menor viscosidade, o caso dos ligantes convencionais, tornam as misturas betuminosas menos rígidas e mais propícias a apresentar a deformação permanente nas altas temperaturas (Mahboub e Little, 1988; Barros et al., 2015).

0 teor de ligante asfáltico é outro fator que influencia na deformação permanente de misturas asfálticas dependendo do tipo de ligante utilizado (Erkens, 2002; Gardete, 2006; Moura, 2010; Nascimento et al., 2015). Nas seções experimentais da National Center Asphalt Technology (NCAT) e relatadas por Brown et al. (2004), a adição de 0,5\% de ligante com Performance Grade (PG) 64-22 acima do teor de projeto aumentou em $50 \%$ a deformação permanente. Entretanto, o mesmo acréscimo com um ligante de $P G$ 76-22 não resultou em aumento do dano.

Em relação ao agregado mineral, a granulometria das misturas é definida a partir do simples enquadramento dentro de faixas especificadas que não fornecem garantia de uma boa durabilidade e desempenho. Por isso, têm-se buscado métodos racionais e sistemáticos de seleção granulométrica, dentre os quais se têm o método Bailey e o método FAD, ambos com foco na deformação permanente.

0 método Bailey foi desenvolvido pelo engenheiro Robert Bailey do Departamento de Transportes de Illinois, sendo refinado por Vavrik et al. (2001, 2002a, 2002b), com objetivo de melhorar o desempenho das misturas asfálticas em relação à durabilidade, pois orienta a composição de um esqueleto mineral com características das misturas densas e descontínuas, proporcionando um maior intertravamento e resistência à deformação permanente. 0 método avalia a granulometria através de limites para três parâmetros: proporção de Agregado Graúdo (AG), proporção Graúda do Agregado Fino (GAF) e proporção Fina do Agregado Fino (FAF), de acordo com o Tamanho Máximo Nominal (TMN) e do comportamento graúdo ou miúdo da mistura (Cunha, 2004; Marques, 2004; Mendes e Marques, 2012).

0 método FAD, proposto por Kim (2006), é uma ferramenta que avalia a estrutura granulométrica de misturas asfálticas e tem por objetivo um esqueleto pétreo estável e resistente à deformação permanente a partir de um contato efetivo entre as partículas graúdas (maiores que 1,18 $\mathrm{mm}$ ), chamadas de agregados dominantes e que compõem a FAD. Os agregados mantêm um espaçamento constante e com um contato efetivo que garante um esqueleto com boa resistência ao dano quando a proporção relativa entre a quantidade retida de duas peneiras consecutivas fique no intervalo entre 0,43 e 2,33. Esse contato 
granular é avaliado por meio da porosidade, medida adimensional e indica o comportamento da mistura à deformação permanente (Ferreira et al., 2015; Bastos, 2015; Ferreira et al., 2016).

Diante da influência do ligante asfáltico e da granulometria do agregado no comportamento mecânico dos concretos asfálticos, esta pesquisa tem por objetivo avaliar o ligante asfáltico, em relação ao tipo e ao teor, e da granulometria oriunda de uma fonte única de agregado, quanto à avaliação das metodologias Bailey e FAD e ainda das faixas granulométricas $\mathrm{B}$ e C do DNIT quanto à resistência na deformação permanente de misturas asfálticas por meio do ensaio uniaxial de carga repetida. Além disso, de correlacionar as propriedades reológicas e o teor do ligante asfáltico, a porosidade FAD e a Proporção AG com os FNs apresentados pelas misturas.

\section{MATERIAIS E MÉTODOS}

Para o desenvolvimento deste trabalho, utilizaram-se 3 ligantes asfálticos, 4 granulometrias e 2 métodos de dosagem, totalizando 24 misturas asfálticas. Os cimentos asfálticos utilizados foram o ligante 50/70, AMP 60/85 Compaflex e o HiMA, ambos modificados pelo polímero SBS na percentagem de 4,5\% e 7,5\%, respectivamente. Os ensaios de caracterização realizados e os resultados obtidos estão na Tabela 1.

Tabela 1: Resultados dos ensaios de caracterização dos ligantes asfálticos

\begin{tabular}{|c|c|c|c|c|c|}
\hline \multirow{2}{*}{$\begin{array}{c}\text { Li- } \\
\text { gante }\end{array}$} & \multirow{2}{*}{ Ensaio } & \multicolumn{3}{|c|}{ Medida } & \multirow{2}{*}{ Limites } \\
\hline & & $50 / 70$ & AMP 60/85 & HiMA & \\
\hline- & $P G$ & $58 \mathrm{H}-28$ & $70 \mathrm{H}-22$ & $76 \mathrm{E}-28$ & - \\
\hline \multirow{6}{*}{ 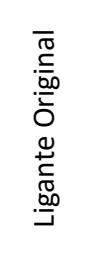 } & \multirow{3}{*}{$\begin{array}{l}\text { Viscosidade } \\
\text { T } 316^{1}(2013)\end{array}$} & $333\left(135^{\circ} \mathrm{C}\right)$ & $1025\left(135^{\circ} \mathrm{C}\right)$ & $872\left(135^{\circ} \mathrm{C}\right)$ & \\
\hline & & $138\left(150^{\circ} \mathrm{C}\right)$ & $514\left(150^{\circ} \mathrm{C}\right)$ & $317\left(150^{\circ} \mathrm{C}\right)$ & - \\
\hline & & $68\left(177^{\circ} \mathrm{C}\right)$ & $225\left(177^{\circ} \mathrm{C}\right)$ & $122\left(177^{\circ} \mathrm{C}\right)$ & \\
\hline & \multirow{3}{*}{$\begin{array}{l}D S R^{2}\left|G^{*}\right| / \operatorname{sen}(\phi) \\
\mathrm{T} 315^{1}(2012)\end{array}$} & $2,96\left(58^{\circ} \mathrm{C}\right)$ & $2,09\left(64^{\circ} \mathrm{C}\right)$ & $2,53\left(70^{\circ} \mathrm{C}\right)$ & \\
\hline & & $1,32\left(64^{\circ} \mathrm{C}\right)$ & $1,14\left(70^{\circ} \mathrm{C}\right)$ & $1,67\left(76^{\circ} \mathrm{C}\right)$ & $\geq 1,00 \mathrm{kPa}$ \\
\hline & & $0,62\left(70^{\circ} \mathrm{C}\right)$ & $0,65\left(76^{\circ} \mathrm{C}\right)$ & $1,21\left(82^{\circ} \mathrm{C}\right)$ & \\
\hline \multirow{9}{*}{ 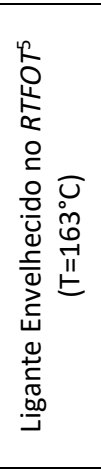 } & $\begin{array}{l}\text { Perda de Massa } \\
\text { T } 240^{1}(2013)\end{array}$ & $-0,04$ & $-0,08$ & $-0,04$ & $< \pm 1,00 \%$ \\
\hline & \multirow{3}{*}{$\begin{array}{l}D S R^{2}\left|G^{*}\right| / \operatorname{sen}(\phi) \\
\mathrm{T} 315^{1}(2012)\end{array}$} & $4,93\left(58^{\circ} \mathrm{C}\right)$ & $4,18\left(64^{\circ} \mathrm{C}\right)$ & $4,08\left(70^{\circ} \mathrm{C}\right)$ & \multirow{3}{*}{$\geq 2,20 \mathrm{kPa}$} \\
\hline & & $2,09\left(64^{\circ} \mathrm{C}\right)$ & $2,25\left(70^{\circ} \mathrm{C}\right)$ & $2,58\left(76^{\circ} \mathrm{C}\right)$ & \\
\hline & & $0,93\left(70^{\circ} \mathrm{C}\right)$ & $1,27\left(76^{\circ} \mathrm{C}\right)$ & $1,71\left(82^{\circ} \mathrm{C}\right)$ & \\
\hline & \multirow{5}{*}{ 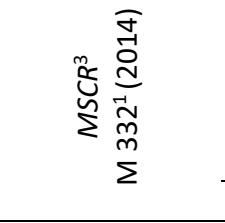 } & \multirow{4}{*}{$1,91\left(58^{\circ} \mathrm{C}\right)$} & \multirow{4}{*}{$1,41\left(70^{\circ} \mathrm{C}\right)$} & \multirow{4}{*}{$0,21\left(76^{\circ} \mathrm{C}\right)$} & $S[2,0<j n r \leq 4,5]$ \\
\hline & & & & & $H[1,0<j n r \leq 2,0$ \\
\hline & & & & & $V[0,5<$ jnr $\leq 1,0]$ \\
\hline & & & & & $E[0,0<j n r \leq 0,5]$ \\
\hline & & $5,50 \%$ & $62,70 \%$ & $96,30 \%^{7}$ & $\leq 75 \%$ \\
\hline \multirow{9}{*}{ 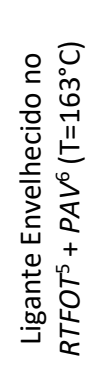 } & \multirow{3}{*}{$\begin{array}{l}D S R^{2}\left|G^{*}\right| \cdot \operatorname{sen}(\phi) \\
\mathrm{T} 315^{1}(2012)\end{array}$} & $11198\left(19^{\circ} \mathrm{C}\right)$ & $7949\left(19^{\circ} \mathrm{C}\right)$ & $2482\left(19^{\circ} \mathrm{C}\right)$ & \\
\hline & & $7442\left(22^{\circ} \mathrm{C}\right)$ & $5382\left(22^{\circ} \mathrm{C}\right)$ & $1631\left(22^{\circ} \mathrm{C}\right)$ & $\leq 6000 \mathrm{kPa}$ \\
\hline & & $4998\left(25^{\circ} \mathrm{C}\right)$ & $3449\left(25^{\circ} \mathrm{C}\right)$ & $1036\left(25^{\circ} \mathrm{C}\right)$ & \\
\hline & \multirow{3}{*}{$\begin{array}{l}B B R^{4} \text { Módulo de rigidez - S } \\
T 313^{1}(2012)\end{array}$} & $52\left(-6^{\circ} \mathrm{C}\right)$ & $42\left(-6^{\circ} \mathrm{C}\right)$ & $43\left(-6^{\circ} \mathrm{C}\right)$ & \\
\hline & & $135\left(-12^{\circ} \mathrm{C}\right)$ & $86\left(-12^{\circ} \mathrm{C}\right)$ & $80\left(-12^{\circ} \mathrm{C}\right)$ & $\leq 300 \mathrm{MPa}$ \\
\hline & & $278\left(-18^{\circ} \mathrm{C}\right)$ & $186\left(-18^{\circ} \mathrm{C}\right)$ & $119\left(-18^{\circ} \mathrm{C}\right)$ & \\
\hline & \multirow{3}{*}{$\begin{array}{l}\text { Coeficiente angular }-\mathrm{m} \\
\mathrm{T}_{313^{1}(2012)}\end{array}$} & $0,428\left(-6^{\circ} \mathrm{C}\right)$ & $0,439\left(-6^{\circ} \mathrm{C}\right)$ & $0,454\left(-6^{\circ} \mathrm{C}\right)$ & \\
\hline & & $0,330\left(-12^{\circ} \mathrm{C}\right)$ & $0,391\left(-12^{\circ} \mathrm{C}\right)$ & $0,325\left(-12^{\circ} \mathrm{C}\right)$ & $\geq 0,300$ \\
\hline & & $0,316\left(-18^{\circ} \mathrm{C}\right)$ & $0,286\left(-18^{\circ} \mathrm{C}\right)$ & $0,333\left(-18^{\circ} \mathrm{C}\right)$ & \\
\hline
\end{tabular}

${ }^{1} \mathrm{AASHTO} ;{ }^{2}$ Dynamic Shear Rheometer; ${ }^{3}$ Multiple Stress Creep and Recovery; ${ }^{4}$ Bending Beam Rheometer; $\quad{ }^{5}$ Rolling Thin Film Oven Test; ${ }^{6}$ Pressure Aging Vessel; 7 Valor do Jnrdiff superior ao limite de 75\%, entretanto, a literatura tem mostrado que ligantes com alto teor de modificação, principalmente por polímero SBS, apresentam alta sensibilidade à variação de tensão (Domingos e Faxina, 2015; Huang e Tang, 2015; Sumeraj, 2016), o que pode representar uma limitação deste parâmetro, ou seja, para ligantes altamente modificados o Jnrdiff não tem significado físico, sendo discutida a sua retirada da especificação; $S$ - Standard (tráfego padrão); $H$ - High (tráfego pesado); V -Very High (tráfego muito pesado); $E$ - Extremely High (tráfego extra pesado). 
Os agregados são de origem vulcânica (diabásio), pertencentes à geomorfologia do Planalto Basáltico do Rio Grande do Sul, e constituídos por 5 tipos de agregados que estão descritos, juntamente com os ensaios de caracterização, na Tabela 2. A adesividade (DNER-ME 078/94) foi satisfatória para os três ligantes asfálticos sem incorporação da cal hidratada.

Tabela 2: Resultados dos ensaios de caracterização dos agregados

\begin{tabular}{|c|c|c|c|c|c|c|}
\hline Propriedades & Norma & Brita 1" & Brita 3/4" & $\begin{array}{l}\text { Brita } \\
3 / 8^{\prime \prime}\end{array}$ & $\begin{array}{l}\text { Pó } \\
\text { Grosso }\end{array}$ & $\begin{array}{l}\text { Pó } \\
\text { Fino }\end{array}$ \\
\hline Absorção (\%) & DNER-ME 081/98 & 1,119 & 1,208 & 1,233 & - & - \\
\hline Massa específica real $\left(\mathrm{g} / \mathrm{cm}^{3}\right)$ & DNER-ME 081/98 & 2,973 & 2,984 & 2,972 & 3,008 & 3,010 \\
\hline Massa específica aparente $\left(\mathrm{g} / \mathrm{cm}^{3}\right)$ & DNER-ME 081/98 & 2,878 & 2,880 & 2,867 & - & - \\
\hline Desgaste ou perda à abrasão (\%) & DNER-ME 035/98 & - & 21,30 & - & - & - \\
\hline Sanidade (\%) & DNER-ME 089/94 & & 1,22 & & - & - \\
\hline Equivalente de areia (\%) & DNER-ME 054/97 & - & - & - & \multicolumn{2}{|c|}{60,8} \\
\hline
\end{tabular}

Elaborou-se 4 granulometrias, sendo as duas convencionais (CON FXB e CON FXC) por tentativa e erro simplesmente enquadradas nas Faixas B e C (DNIT 031, 2006). Após aplicou-se ajustes granulométricos nestas duas granulometrias até que as proporções AG, GAF e FAF do método Bailey fossem enquadradas dentro ou o mais próximo dos intervalos propostos para cada parâmetro, respeitando os limites das Faixas B e C, originando as duas granulometrias Bailey (BAI FXB e BAI FXC). A composição de agregados, granulométrica e os parâmetros do método Bailey para as 4 granulometrias estão apresentadas na Tabela 3, enquanto que a Figura 1 apresenta as curvas granulométricas.

Tabela 3: Composição de agregados, granulométrica e Bailey das misturas

\begin{tabular}{|c|c|c|c|c|}
\hline Granulometria & $\begin{array}{c}\text { Convencional Faixa B } \\
\text { (CON FXB) }\end{array}$ & $\begin{array}{l}\text { Bailey Faixa B } \\
\text { (BAI FXB) }\end{array}$ & $\begin{array}{c}\text { Convencional Faixa C } \\
\text { (CON FXC) }\end{array}$ & $\begin{array}{c}\text { Bailey Faixa C } \\
\text { (BAI FXC) }\end{array}$ \\
\hline Agregados & \multicolumn{4}{|c|}{ Composição de Agregados (\%) } \\
\hline Brita 1" & 14 & 17 & 0 & 0 \\
\hline Brita 3/4" & 11 & 17 & 20 & 30 \\
\hline Brita 3/8" & 27 & 19 & 27 & 15 \\
\hline Pó Grosso & 23 & 23 & 26 & 29,5 \\
\hline Pó Fino & 23,5 & 22,5 & 25,5 & 24 \\
\hline \multirow[t]{2}{*}{ Cal Hidratada } & 1,5 & 1,5 & 1,5 & 1,5 \\
\hline & \multicolumn{4}{|c|}{ Composição Granulométrica das Misturas Estudadas } \\
\hline Peneiras mm & \multicolumn{4}{|c|}{$\%$ Passante } \\
\hline $11 / 2^{\prime \prime}$ & 100,0 & 100 & 100,0 & 100,0 \\
\hline $1^{\prime \prime}$ & 99,4 & 99,2 & 100,0 & 100,0 \\
\hline $3 / 4^{\prime \prime}$ & 94,4 & 93,3 & 100,0 & 100,0 \\
\hline $1 / 2^{\prime \prime}$ & 80,8 & 75,0 & 88,0 & 81,0 \\
\hline $3 / 8^{\prime \prime}$ & 73,9 & 65,9 & 79,2 & 70,5 \\
\hline$n^{\circ} 4$ & 45,6 & 43,6 & 49,7 & 49,1 \\
\hline $\mathrm{n}^{\circ} 10$ & 28,3 & 27,6 & 31,0 & 31,3 \\
\hline$n^{\circ} 40$ & 15,1 & 15,1 & 16,9 & 17,1 \\
\hline $\mathrm{n}^{\circ} 80$ & 9,8 & 9,8 & 10,9 & 11,0 \\
\hline \multirow[t]{2}{*}{$n^{\circ} 200$} & 5,1 & 5,0 & 5,5 & 5,5 \\
\hline & \multicolumn{4}{|c|}{ Parâmetros Granulométricos do método Bailey para TMN 19mm } \\
\hline Proporção (limite) & \multicolumn{4}{|c|}{ Valores } \\
\hline AG $(0,60-0,75)$ & 1,09 & 0,65 & 1,41 & 0,72 \\
\hline $\operatorname{GAF}(0,35-0,50)$ & 0,48 & 0,48 & 0,48 & 0,48 \\
\hline $\operatorname{FAF}(0,35-0,50)$ & 0,59 & 0,59 & 0,59 & 0,59 \\
\hline
\end{tabular}

Nota-se que as proporções AF para as 2 granulometrias Bailey ficaram acima do limite proposto pelo método, mesmo após várias tentativas de enquadramento, sendo esta a melhor obtida com os agregados disponíveis, fato este também identificado em estudos como Budny (2012), Mendes e Marques (2012) e Wargha Filho (2013). 0 comportamento graúdo das misturas inicialmente adotado devido a quantidade de material passante na PCP ser menor que 49,9\% em todas as misturas (ASPHALT INSTITUTE, 2011), 
foi confirmado após o processo de dosagem. Encontrou-se em todas as misturas um volume de vazios da fração graúda (VCARuw) maior que a porcentagem de vazios dos agregados graúdos na mistura asfáltica (VCAmix), conforme demonstrado na Tabela 4.
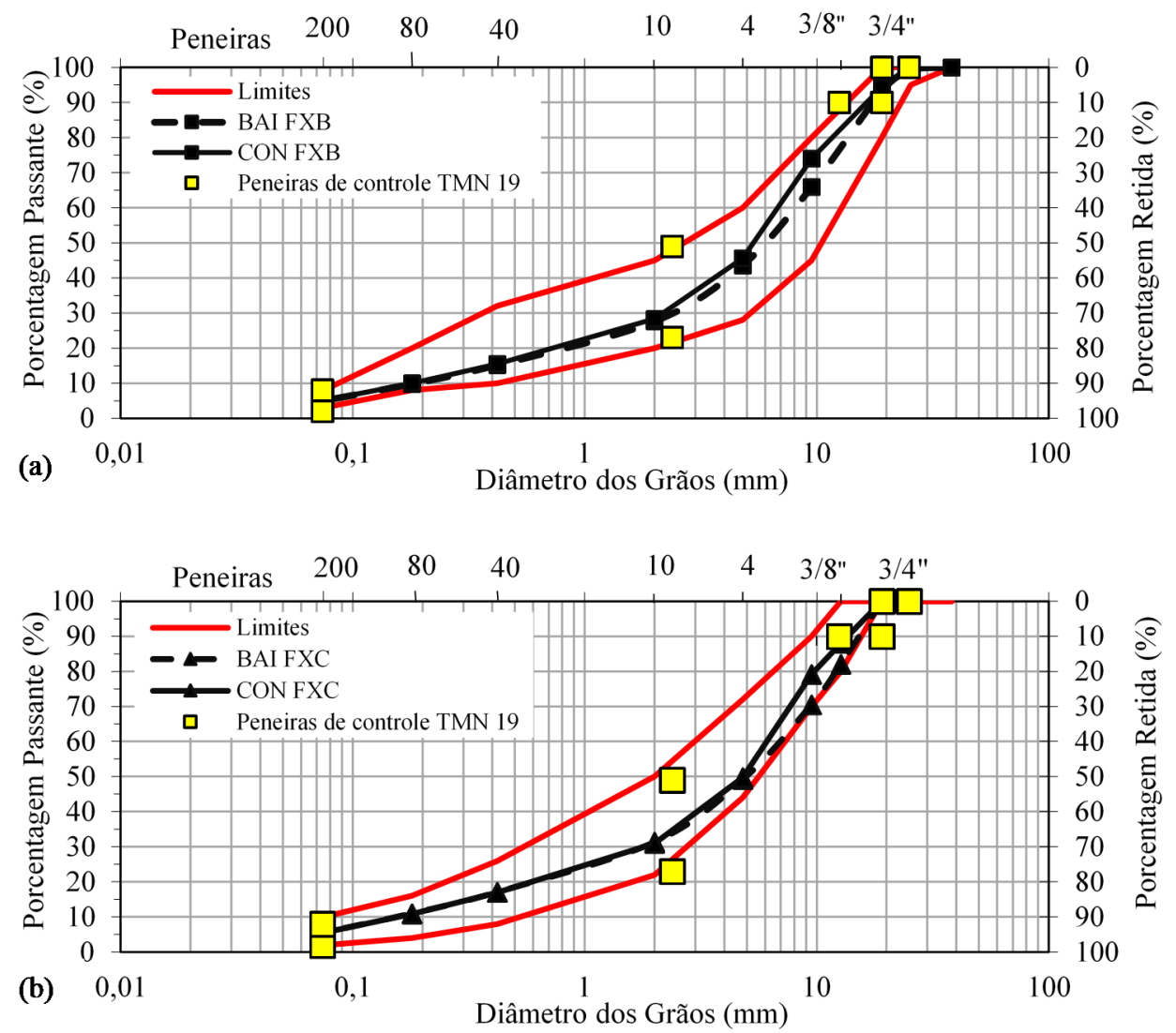

Figura 1. Curva granulométrica das misturas Faixas B (a) e Faixas C (b) DNIT 031 (2006)

Tabela 4 - Avaliação do comportamento das misturas quanto à volumetria

\begin{tabular}{|c|c|c|c|c|c|c|}
\hline Mistura & $\begin{array}{c}\text { S CON FXB } \\
50-70\end{array}$ & $\begin{array}{c}\text { S BAI FXB } \\
50-70\end{array}$ & $\begin{array}{c}\text { S CON FXC } \\
50-70\end{array}$ & $\begin{array}{c}\text { S BAI FXC } \\
50-70\end{array}$ & $\begin{array}{c}\text { S CON FXB } \\
60-85\end{array}$ & $\begin{array}{c}\text { S BAI FXB } \\
60-85\end{array}$ \\
\hline VCA RUW & 55,41 & 55,25 & 54,79 & 54,35 & 55,41 & 55,25 \\
\hline \multirow[t]{2}{*}{ VCAmix } & 50,14 & 48,13 & 53,98 & 53,45 & 50,18 & 48,19 \\
\hline & Graúdo & Graúdo & Graúdo & Graúdo & Graúdo & Graúdo \\
\hline \multirow{2}{*}{ Mistura } & S CON FXC & S BAI FXC & S CON FXB & S BAI FXB & S CON FXC & S BAI FXC \\
\hline & $60-85$ & $60-86$ & HiMA & HiMA & HiMA & HiMA \\
\hline VCARUW & 54,79 & 54,35 & 55,41 & 55,25 & 54,79 & 54,35 \\
\hline \multirow[t]{2}{*}{ VCAmix } & 54,33 & 53,27 & 50,56 & 48,39 & 54,37 & 53,33 \\
\hline & Graúdo & Graúdo & Graúdo & Graúdo & Graúdo & Graúdo \\
\hline \multirow{2}{*}{ Mistura } & M CON FXB & M BAI FXB & M CON FXC & M BAI FXC & M CON FXB & M BAI FXB \\
\hline & $50-70$ & $50-70$ & $50-70$ & $50-70$ & $60-85$ & $60-85$ \\
\hline VCA $_{\text {RUW }}$ & 55,41 & 55,25 & 54,79 & 54,35 & 55,41 & 55,25 \\
\hline \multirow[t]{2}{*}{ VCAmix } & 50,75 & 48,79 & 54,60 & 53,72 & 50,89 & 48,79 \\
\hline & Graúdo & Graúdo & Graúdo & Graúdo & Graúdo & Graúdo \\
\hline \multirow{2}{*}{ Mistura } & M CON FXC & M BAI FXC & M CON FXB & M BAI FXB & M CON FXC & M BAI FXC \\
\hline & $60-85$ & $60-85$ & HiMA & HiMA & HiMA & HiMA \\
\hline $\mathrm{VCA}_{\mathrm{RUW}}$ & 54,79 & 54,35 & 55,41 & 55,25 & 54,79 & 54,35 \\
\hline \multirow[t]{2}{*}{ VCAmix } & 54,69 & 53,81 & 51,01 & 48,98 & 54,68 & 54,26 \\
\hline & Graúdo & Graúdo & Graúdo & Graúdo & Graúdo & Graúdo \\
\hline
\end{tabular}

Além do método Bailey, verificou-se o comportamento das granulometrias das 24 misturas quanto ao método FAD calculando-se as porosidades após o processo de dosagem, conforme a Equação 1, que considera no cálculo a densidade aparente da mistura de agregados, densidade máxima medida, teor de ligante e volume de vazios da mistura. Para porosidade inferior a 48\% têm-se um esqueleto mineral 
potencialmente resistente à deformação permanente, pois quanto maior a quantidade de peneiras na composição da FAD maior é a quantidade de diferentes tamanhos de agregados que estão interagindo entre si e formando o esqueleto mineral. Valores superiores a $52 \%$ são um indicativo de susceptibilidade à deformação permanente e valores intermediários a estes dois limites são chamados porosidades marginais no qual não se tem uma garantia quanto a capacidade de intertravamento da estrutura de agregados.

$$
\eta_{\mathrm{FAD}}=\frac{\mathrm{V}_{\mathrm{IC}, \mathrm{ag}}+\mathrm{VAM}}{\mathrm{V}_{\mathrm{TM}}-\mathrm{V}_{\mathrm{ag}>\mathrm{FAD}}}
$$

onde, $\eta_{F A D}$ : porosidade FAD (\%); $V_{I C, a g}$ : volume de agregados intersticiais (menores do que a FAD); $V A M$ : volume de vazios no agregado mineral; $V_{T M}$ : volume total da mistura; $V_{a g>F A D}$ : volume de agregados flutuantes (maiores do que a FAD).

As misturas foram dosadas pela metodologia Superpave (AASHTO M 323,2013) com 100 giros e os critérios de projeto nível 1 (critério volumétrico), dependente do tráfego e da importância da rodovia, e pelo método de dosagem Marshall (ASTM D 2926,2004) com 75 golpes. Os teores de projeto obtidos para as 24 misturas asfálticas estão apresentados na Figura 2. Verifica-se que todas as misturas Marshall apresentaram teores de ligante superior às misturas Superpave, no qual o menor aumento no teor foi de $0,4 \%$ e o maior de $1,2 \%$. Além disso, destaca-se que os teores de ligante obtidos na dosagem Superpave não atendem ao teor mínimo requerido de 4,5\% para camada de rolamento da norma DNIT 031 (2006). Com a utilização desses dois métodos de dosagem foi possível analisar a influência da variação do teor de ligante para uma mesma mistura no comportamento à deformação permanente.

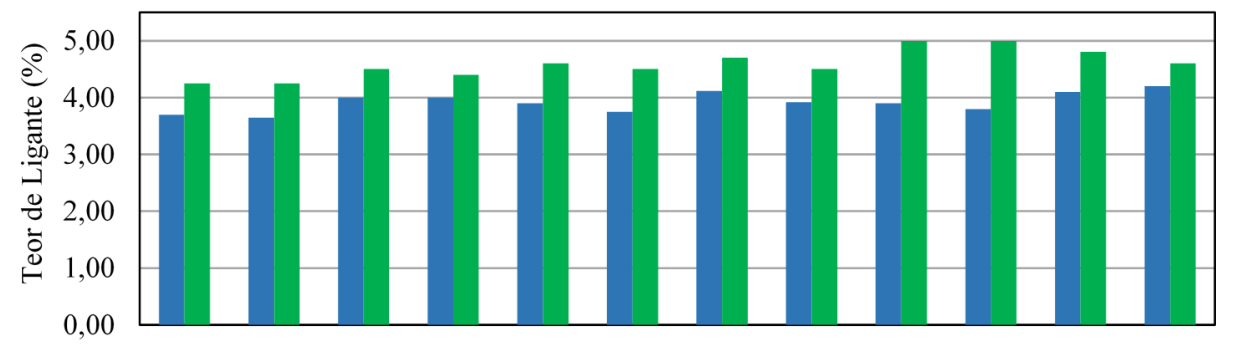

\begin{tabular}{|c|c|c|c|c|c|c|c|c|c|c|c|c|}
\hline & 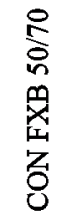 & 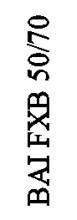 & 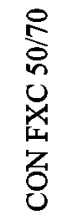 & 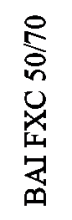 & 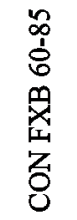 & 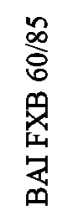 & 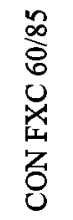 & 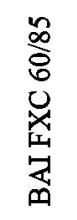 & 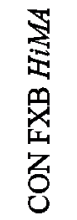 & 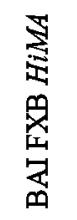 & 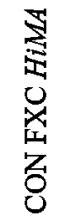 & 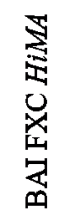 \\
\hline Superpave & 3,70 & 3,65 & 4,00 & 4,00 & 3,90 & 3,75 & 4,12 & 3,92 & 3,90 & 3,80 & 4,10 & 4,20 \\
\hline Marshall & 4,25 & 4,25 & 4,50 & 4,40 & 4,60 & 4,50 & 4,70 & 4,50 & 5,00 & 5,00 & 4,80 & 4,60 \\
\hline
\end{tabular}

Figura 2. Teor de ligante obtido para as 24 misturas asfálticas

Para avaliação da resistência à deformação permanente realizou-se o ensaio uniaxial de carga repetida, conforme norma AASHTO TP 79 (2012), que também atende a ABNT NBR 16505 (2016). Como parâmetros de ensaio adotou-se o tempo de aplicação de carga de $0,1 \mathrm{~s}$, tempo de repouso de $0,9 \mathrm{~s}$, tensão de $204 \mathrm{kPa}$, tensão de repouso de 10,2 kPa, tensão de pré-carregamento de $15 \mathrm{kPa}$ com duração de $60 \mathrm{~s}$, temperatura de ensaio de $60^{\circ} \mathrm{C}$ e tempo mínimo de condicionamento das amostras de 3 horas. 0 critério de parada do ensaio foi de $5 \%$ da deformação ou 10000 ciclos.

Foram moldadas 3 amostras por mistura nas dimensões 10 x $15 \mathrm{~cm}$ no Compactador Giratório Superpave com volume de vazios de $7 \pm 0,5 \%$ e ensaiadas na Universal Test Machine. A curva de deformação plástica vertical uniaxial de cada corpo de prova foi ajustada ao modelo de Francken, que é uma combinação dos modelos de potência e exponencial. 
Com os resultados do ensaio uniaxial de carga repetida, buscou-se correlacionar os FNs das misturas asfálticas com as propriedades reológicas, Jnr e $P G$ de alta, dos ligantes asfálticos, teor de ligante de projeto, proporção AG e porosidade FAD. Além disso, construiu-se um modelo através de uma regressão linear múltipla, que é uma técnica estatística para construção de modelos que descrevem a relação entre várias variáveis explicativas de uma determinada propriedade, neste caso o FN.

\section{APRESENTAÇÃO E DISCUSSÃO DOS RESULTADOS}

Os resultados do ensaio uniaxial de carga repetida estão apresentados na Figura 3. Nota-se uma influência significativa do tipo e teor do ligante asfáltico nos resultados apresentados pelas misturas. Quanto maior a quantidade de modificação no ligante asfáltico por polímero SBS maior o $F N$ das misturas em decorrência da melhor absorção dos esforços e da maior recuperação elástica que as modificações conferem ao concreto asfáltico, fato este também constatado em estudos como Onofre et al. (2013), Barros et al. (2015), e Santagata et al. (2015). Já um aumento no teor de ligante asfáltico reduziu o FN das misturas asfálticas.

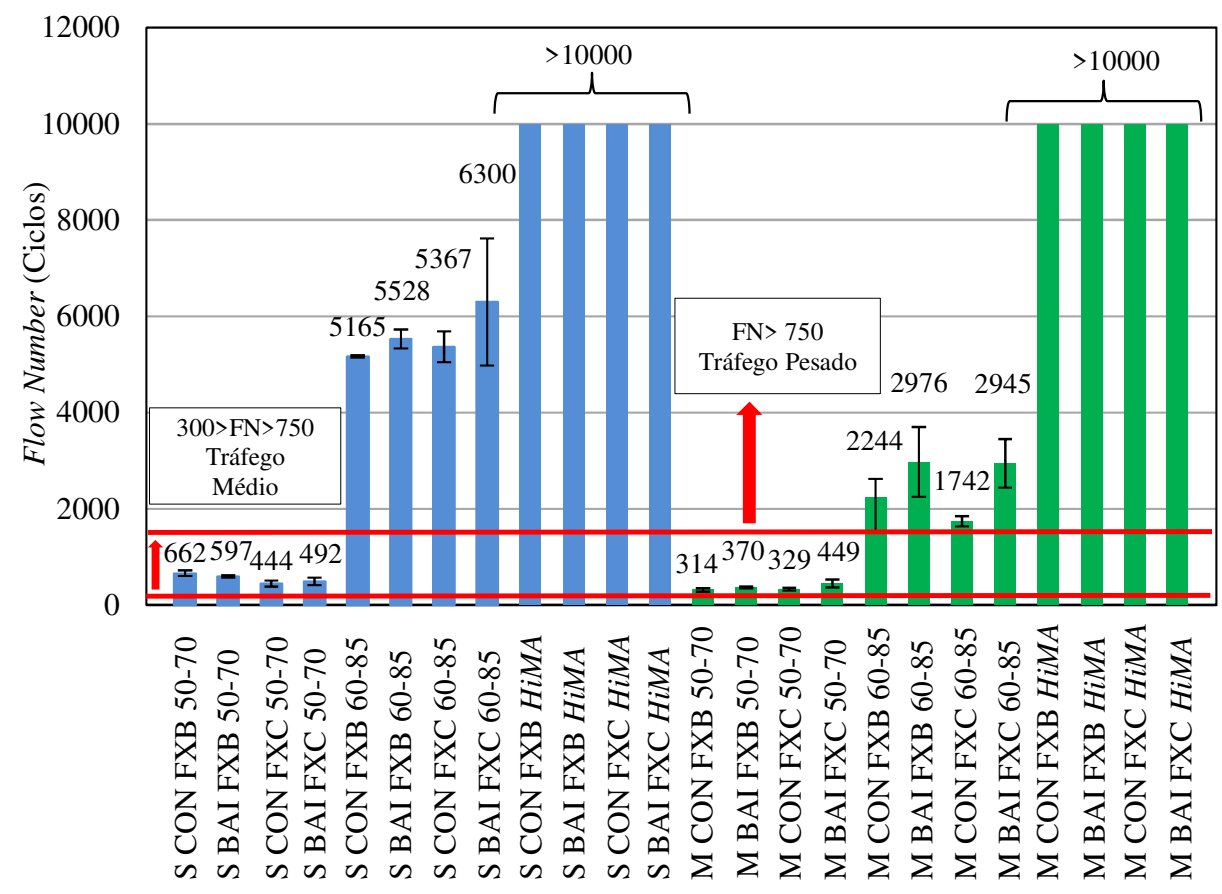

Figura 3. Flow Number obtido para as 24 misturas asfálticas

As misturas com ligante 50/70 apresentaram os menores $F N$, enquanto as misturas com ligante AMP 60/85 valores intermediários e as misturas com ligante HiMA não atingiram a deformação de 5\% em 10000 ciclos. Segundo os critérios de Nascimento (2008), as misturas com o ligante 50/70 seriam adequadas para um tráfego médio de $3 \times 10^{6}$ a $1 \times 10^{7}(300<F N<750)$, enquanto as demais, 16 misturas com ligante modificado, compatíveis com um tráfego pesado de $1 \times 10^{7}$ a $3 \times 10^{7}(F N>750)$. Portanto, para as misturas desta pesquisa que considera apenas uma fonte de agregado mineral é necessário modificar o tipo de ligante asfáltico para alterar a classificação quanto ao tráfego, sendo que as modificações na granulometria e no teor de ligante não apresentaram tal potencial. Cabe salientar que variações maiores no teor de ligante asfáltico que as apresentadas neste trabalho e alterações na forma, mineralogia, angularidade e textura dos agregados podem alterar a classificação quanto ao tipo de tráfego, entretanto não foram objetos deste estudo.

Considerando os limites sugeridos em Bastos et al. (2017), as misturas com ligante 50/70 seriam classificadas para um tráfego pesado de $1 \times 10^{7}$ a $3 \times 10^{7}(300<F N<1000)$, e as misturas com os ligantes 
modificados à um nível de tráfego extremamente pesado maior que $3 \times 10^{7}(F N>1000)$.

Ao se analisar os ensaios de caracterização reológica dos ligantes asfálticos com o comportamento à deformação permanente encontra-se coerência com os resultados apresentados. No ensaio com ligante envelhecido no RTFOT utilizando o $D S R$, que permite ter um indicativo do comportamento do material ao afundamento em trilha de roda imediatamente após a execução do revestimento através da relação $\left|G^{*}\right| / \operatorname{sen} \varphi$, encontrou-se o maior valor da relação para o ligante HiMA, seguido pelo AMP 60/85 e 50/70, indicando uma maior recuperação elástica dos ligantes modificados na temperatura do ensaio uniaxial de carga repetida.

Além disso, é possível relacionar o parâmetro reológico Jnr obtido no ensaio $M S C R$ e o $P G$ de alta temperatura dos ligantes asfálticos com a deformação permanente. Quanto maior o Jnr dos ligantes asfálticos menor a capacidade do ligante de recuperar as deformações sofridas pela ação cisalhante do tráfego. $O P G$ classifica o material quanto ao comportamento em função do ambiente em que será implantada a mistura asfáltica, considerando as temperaturas do pavimento ao longo da sua vida útil e do tráfego previsto (NCHRP, 2011).

A Figura 4 apresenta as correlações dos FNs das misturas com o Jnr (a) e o $P G$ de alta temperatura (b) dos ligantes asfálticos. Nota-se que os $\mathrm{R}^{2}$ obtidos indicam forte correlação do Jnr e do $P G$ com a resistência à deformação permanente, tanto ao se analisar separadamente por método de dosagem como pelo conjunto todo de dados. A boa correlação do Jnr e o $F N$ também foi identificada em estudos como D'Angelo (2009) $\left(\mathrm{R}^{2}\right.$ de 0,75 a 0,93) e Domingos et al. (2017) $\left(\mathrm{R}^{2}=0,74\right)$. Além disso, conforme esperado, à medida que aumenta o $P G$ do ligante asfáltico utilizado na mistura tem-se um maior valor de $F N$.
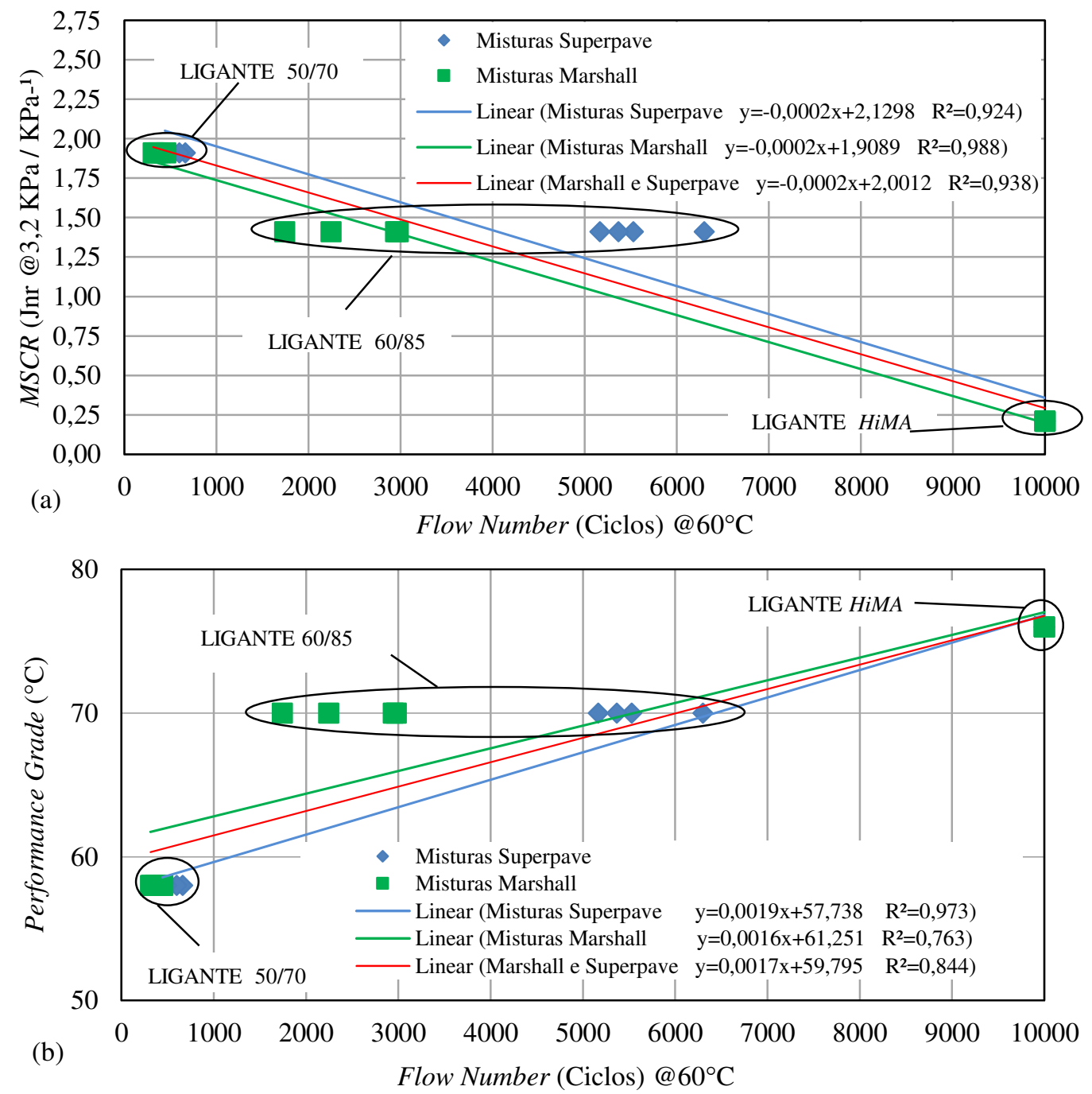

Figura 4. Correlação do Jnr (a) e $P G$ de alta temperatura (b) dos ligantes com os FNs 
O valor de Jnr do ligante HiMA o classifica como Extreme (tráfego extra pesado) com tráfego permanente e maior que $3 \times 10^{7}$ e velocidade menor que $20 \mathrm{~km} / \mathrm{h}$, enquanto que os ligantes AMP 60/85 e 50/70

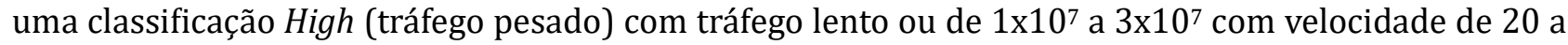
70 km/h (Bahia, 2014; AASHTO M332, 2014). A classificação High do ligante 50/70 está em desacordo com o nível de tráfego sugerido por Nascimento (2008) e de acordo os níveis de tráfego sugerido por Bastos et al. (2017). Entretanto, a classificação High do ligante AMP 60/85 não é compatível com o tráfego extremamente pesado de Bastos et al. (2017), conforme os resultados obtidos nesta pesquisa.

A variação no teor de ligante também influenciou consideravelmente nos $F N$ obtidos pelas misturas, exceto nas misturas com ligante HiMA até 10000 ciclos. Para as misturas com ligante 50/70, a redução no teor de ligante aumentou de $10 \%$ a $111 \%$ o FN, enquanto que para o ligante AMP 60/85 a redução no teor aumentou o $F N$ de $86 \%$ a $208 \%$. Como nas misturas Marshall o teor de ligante é superior às misturas Superpave, essa maior quantidade de ligante asfáltico reduz o atrito entre os agregados, resultando numa maior susceptibilidade de desenvolver à deformação permanente ao aumentar-se o teor de ligante.

A correlação FN versus teor de ligante, Figura 5, apresenta bons $\mathrm{R}^{2}$ e mostra uma maior susceptibilidade das misturas com ligante AMP 60/85 em relação à variação no teor. A modificação de $0,1 \%$ no teor de ligante das misturas com 50/70 resulta em uma variação de aproximadamente 35 ciclos no FN, enquanto nas misturas com o ligante AMP 60/85 a variação é de 412 ciclos.

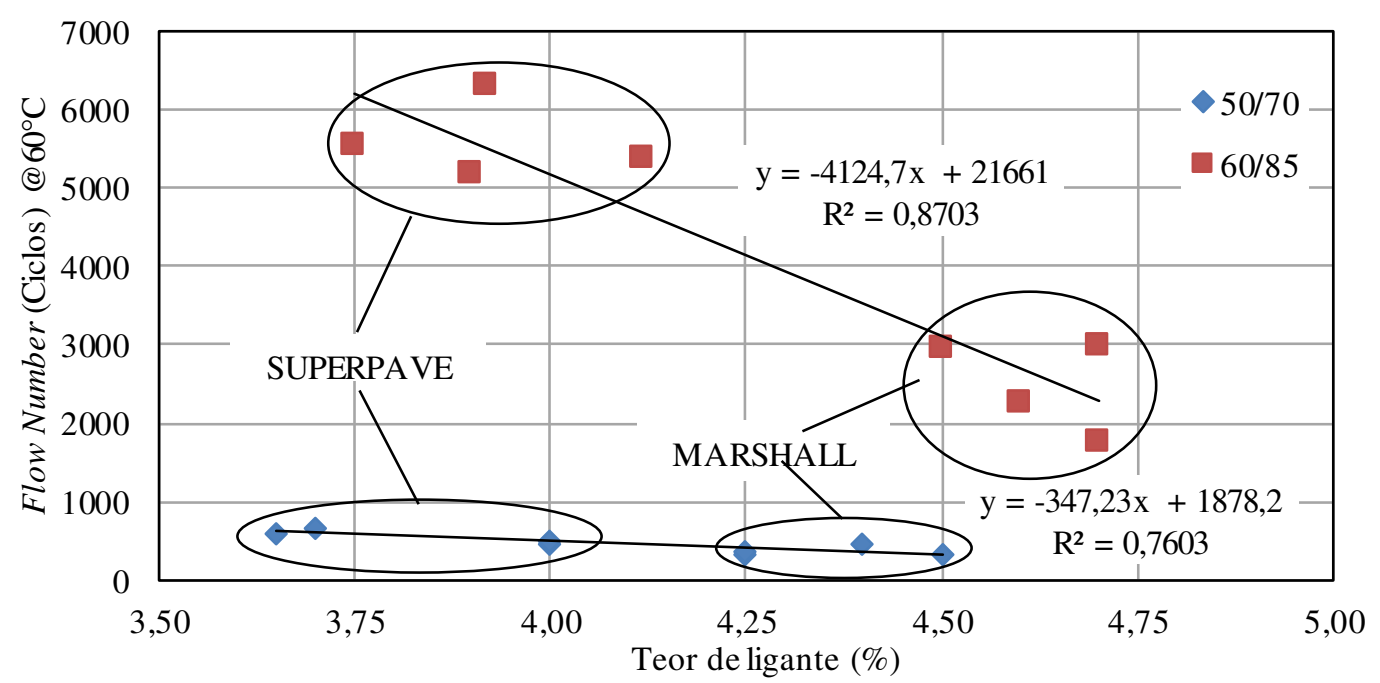

Figura 5. Correlação Teor de Ligante de projeto (\%) e $F N$ obtido nas misturas asfálticas

De modo geral, outros estudos que utilizaram o ligante 50/70 como Nascimento (2008), com $P G$ de 64-22 e agregados de origem gnaisse-granítica de Juiz de Fora-MG, encontrou FN variando de 112 a 531; Onofre (2012) com $P G$ de 64-22 da Replan encontrou $F N$ de 1977 com agregado basáltico de São Paulo e 124 com agregado granítico do Ceará; Com esse mesmo agregado granítico e um ligante de PG 70-18 da Lubnor o autor encontrou $F N$ de 490; Centofante (2016) com o mesmo ligante 50/70 desta pesquisa e agregado basáltico ácido (Riodacito) do Rio Grande do Sul (RS) encontrou FNs de 60, 150, 262 e 540 para misturas com incorporação de fresado nos teores de 0,10, 20 e 30\%, respectivamente. Com isso, verifica-se que os FNs obtidos pelos autores foram próximos ou inferiores aos obtidos nesta pesquisa, com exceção da mistura com agregado basáltico de Onofre (2012), o que condiciona, em termos práticos, misturas com este tipo de ligante adequado à um tráfego médio conforme níveis de tráfego estabelecidos por Nascimento (2008). Para tráfegos pesados os ligantes modificados são mais viáveis tecnicamente para obtenção de $F N$ acima de 750.

Destaca-se a influência dos agregados no comportamento à deformação permanente nos resultados de Onofre (2012) e Centofante (2016). 0 primeiro autor encontrou para o mesmo ligante 50/70 FNs 
opostos ao utilizar um agregado basáltico (1977) e granítico (124) e a autora com o mesmo ligante $50 / 70$ desta pesquisa, porém com agregado de origem diferente desta pesquisa, encontrou $F N$ para a mistura sem incorporação de fresado de 60 (o menor $F N$ desta pesquisa foi 314). Nota-se que a influência do agregado cresce quando se considera diferentes fontes de agregados, pois se tem distintas mineralogias, formas, texturas e rugosidades, diferentemente ao se considerar modificações apenas na granulometria para uma mesma fonte de agregado, no caso desta pesquisa, que mostrou como mais influente o tipo e teor de ligante asfáltico.

Esta influência do ligante asfáltico é corroborado por Centofante (2016), pois para o mesmo agregado só foi possível aumentar o $F N$ com a incorporação de ligante envelhecido na mistura (fresado), e também por Onofre (2012) que ao utilizar um ligante 50/70 de $P G$ maior (70-18) para o agregado granítico aumentou o FN para 490.

A análise com foco na granulometria indica que o ajuste granulométrico proposto pelo método Bailey aumentou de $7 \%$ a $69 \%$ o FN médio das misturas, exceto a S BAI FXB 50/70 com decréscimo de 10\%. Nas misturas Marshall, cujos teores são mais elevados que nas misturas Superpave, o ganho de resistência com o método foi mais significativo. Em teores mais elevados a mistura é mais susceptível a deformar-se, sendo que a resistência aumenta à medida que o esqueleto mineral forneça um maior intertravamento, propriedade conferida pelo método.

Entretanto, apesar do ganho de resistência proporcionado pelo método não se encontrou uma boa correlação, apresentada na Figura 6, entre $F N$ e a proporção AG, que é o fator mais importante para a seleção da mistura, pois avalia a compactação da porção graúda e os vazios resultantes desse arranjo. Valores de AG abaixo do especificado indicam misturas sujeitas a segregação, e valores acima que a fração de agregado graúdo está desbalanceada e as partículas que não são consideradas agregado graúdo tendem a controlar o esqueleto mineral. Conforme esperado, as curvas de tendência indicam que um aumento da proporção AG reduz o valor do $F N$, pois as misturas com a proporção AG acima do especificado apresentam os agregados graúdos dispersos na estrutura, sem um contato granular.

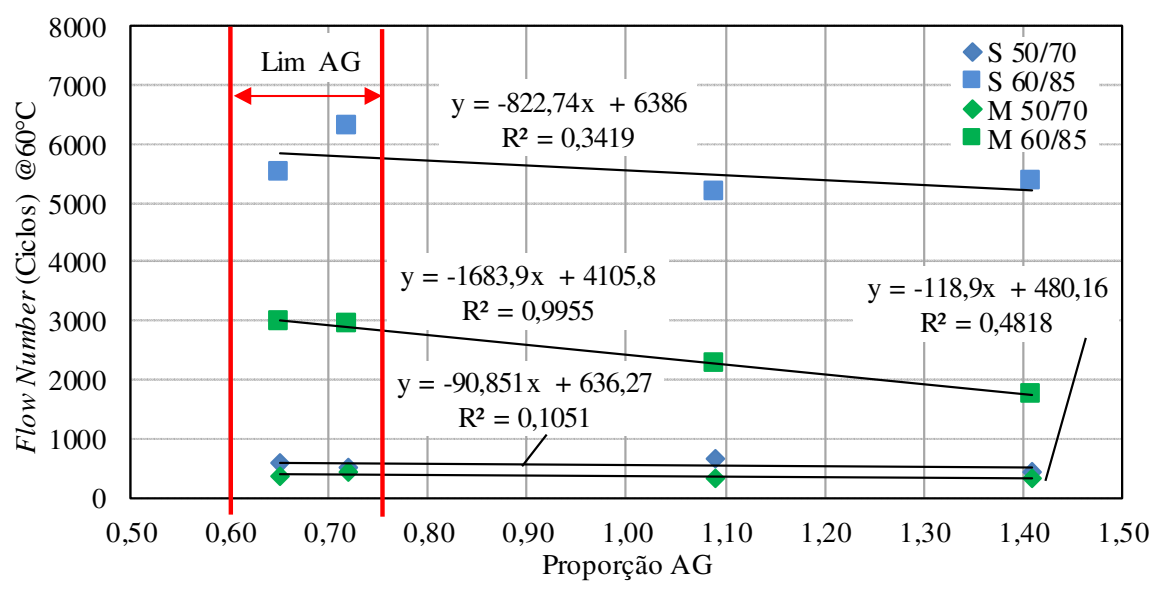

Figura 6. Correlação Proporção AG e FN obtido nas misturas asfálticas

Em relação ao método FAD, na Tabela 5 estão apresentadas as porosidades das misturas asfálticas. As porosidades para todas as misturas são menores que 48, indicando que os tamanhos de agregados os quais compõem a FAD das misturas formam um esqueleto mineral resistente à deformação permanente. Ao se analisar valores de $F N$ de Nascimento (2008), Bastos et al. (2015), Centofante (2016) e Ferreira et al. (2016), nota-se que os FNs das 24 misturas asfálticas desta pesquisa foram iguais ou superiores aos encontrados nos estudos citados anteriormente, indicando coerência com os resultados obtidos. Entretanto, têm-se misturas com porosidades semelhantes e valores de $F N$ distintos, não sendo sensível ao se comparar os comportamentos entre as misturas aqui estudadas com diferentes granulometrias e ligantes asfálticos. 
Tabela 5 - Porosidade FAD e Faixa de Agregado Dominante das misturas

\begin{tabular}{lcclcc}
\hline \multicolumn{1}{c}{ Misturas } & $\begin{array}{c}\text { Porosidade } \\
\text { FAD (\%) }\end{array}$ & FAD & \multicolumn{1}{c}{ Misturas } & $\begin{array}{c}\text { Porosidade } \\
\text { FAD (\%) }\end{array}$ & FAD \\
\hline S CON FX B 50/70 & 42,2 & $4,75-1,18$ & M CON FX B 50/70 & 43,3 & $4,75-1,18$ \\
S BAI FX B 50/70 & 45,1 & $4,75-1,18$ & M BAI FX B 50/70 & 45,1 & $4,75-1,18$ \\
S CON FX C 50/70 & 42,4 & $4,75-1,18$ & M CON FX C 50/70 & 43,4 & $4,75-1,18$ \\
S BAI FX C 50/70 & 35,3 & $12,5-1,18$ & M BAI FX C 50/70 & 35,8 & $12,5-1,18$ \\
S CON FX B 60/85 & 42,3 & $4,75-1,18$ & M CON FX B 60/85 & 43,6 & $4,75-1,18$ \\
S BAI FX B 60/85 & 45,3 & $4,75-1,18$ & M BAI FX B 60/85 & 46,8 & $4,75-1,18$ \\
S CON FX C 60/85 & 42,9 & $4,75-1,18$ & M CON FX C 60/85 & 43,8 & $4,75-1,18$ \\
S BAI FX C 60/85 & 34,9 & $12,5-1,18$ & M BAI FX C 60/85 & 36,0 & $12,5-1,18$ \\
S CON FX B HiMA & 42,7 & $4,75-1,18$ & M CON FX B HiMA & 44,4 & $4,75-1,18$ \\
S BAI FX B HiMA & 45,8 & $4,75-1,18$ & M BAI FX B HiMA & 47,6 & $4,75-1,18$ \\
S CON FX C HiMA & 43,0 & $4,75-1,18$ & M CON FX C HiMA & 44,1 & $4,75-1,18$ \\
S BAI FX C HiMA & 35,2 & $12,5-1,18$ & M BAI FX C HiMA & 36,9 & $12,5-1,18$ \\
\hline
\end{tabular}

Além disso, todas as misturas com granulometria Faixa B apresentam uma FAD de 4,75 mm a 1,18 $\mathrm{mm}$, e por apresentarem porosidade menor que 48, o método indica que esses tamanhos de agregados interagindo entre si formam um esqueleto mineral resistente à deformação permanente. Nas granulometrias Faixas $\mathrm{C}$, as misturas convencionais (CON) apresentam a mesma FAD das misturas com granulometria Faixa B, entretanto as misturas Bailey (BAI) apresentam uma FAD maior, de 12,5 mm a 1,18 $\mathrm{mm}$, indicando que esta granulometria tem agregados maiores formando o esqueleto mineral, reforçando que o método Bailey ajusta o esqueleto mineral para apresentar intertravamento adequado.

A Figura 7 apresenta a correlação entre $F N$ e FAD das misturas separadas por método de dosagem e tipo de ligante asfáltico com bons valores de $\mathrm{R}^{2}$ para as misturas Superpave com ligante AMP 60/85 e Marshall com ligante 50/70, semelhante ao encontrado em Ferreira et al. (2016). Já nas misturas Superpave com ligante 50/70 e Marshall com AMP 60/85 os valores de $\mathrm{R}^{2}$ foram baixos, entretanto, o fato das 24 misturas apresentarem porosidade abaixo de 48 pode ter comprometido a correlação, pois não abrange um espectro maior de porosidade. Conforme esperado, verificou-se em quase todas as correlações que um aumento na porosidade reduz o FN das misturas.

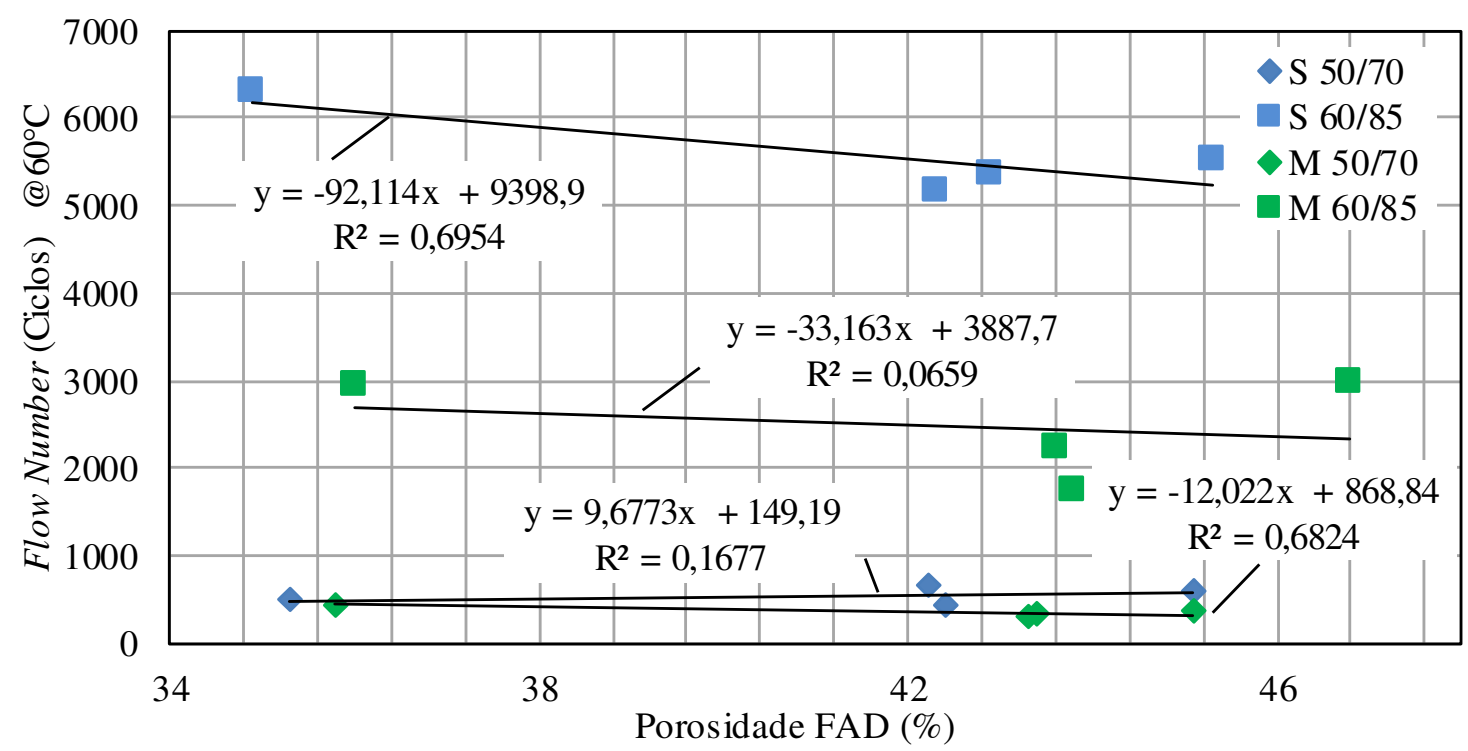

Figura 7. Correlação Porosidade FAD e FN obtido nas misturas asfálticas 
Ao se comparar o método Bailey e FAD, ambos buscam propor composições granulométricas de forma sistemática e racionais compatíveis com a boa durabilidade de uma mistura asfáltica. 0 método Bailey mostrou-se uma ferramenta de rápida avaliação inicial ao se pressupor o comportamento da mistura com base na granulometria e análise dos parâmetros do método. Entretanto, após o processo de dosagem é necessário confirmar o comportamento inicialmente presumido a partir da análise entre o volume de vazios na fração graúda (VCA $\mathrm{RUw}_{\mathrm{W}}$ e o volume de vazios da mistura asfáltica (VCAmix). Além disso, pode-se citar como limitação a ausência de procedimentos para avaliar granulometrias que não se enquadram em todos os critérios do método e a não consideração de outras propriedades do agregado como tamanho, angularidade e textura.

A metodologia FAD também se mostrou um bom indicador quanto à deformação permanente quando se compara os resultados desta pesquisa com outros estudos da literatura, além de considerar parâmetros como densidade aparente da mistura de agregados, densidade máxima medida da mistura, teor de ligante e volume de vazios da mistura, que são propriedades influenciadas pelo agregado e ligante asfáltico. Entretanto, a porosidade, que é o parâmetro de avaliação do método só pode ser calculada após o processo de dosagem.

Quanto às faixas granulométricas, apenas nas misturas Superpave com ligante 50/70 que as misturas com granulometria Faixa B apresentaram uma maior resistência que as misturas com granulometria Faixa C. Tais observações mostram que a utilização de uma granulometria mais grossa (Faixa B) não necessariamente vai conferir uma maior resistência à deformação permanente comparada a uma granulometria mais fina (Faixa C), e sim o importante é a efetividade do contato granular que irá formar o esqueleto mineral, no qual os métodos Bailey e FAD se mostraram uma boa ferramenta.

Por fim, buscou-se construir um modelo do $F N$ em função dos $P G s$ de alta temperatura dos ligantes asfálticos, teores de ligantes de projeto, proporções AG e porosidades FAD das misturas. 0 modelo apresentado pela Equação 2 apresentou um bom $R^{2}$ ajustado $\left(R^{2}=0,85\right)$, indicando um bom ajuste da reta, e uma boa significância global $(\rho<0,05)$, entretanto, ao se analisar o teste de significância individual de cada variável, somente o $P G$ de alta temperatura e o teor de ligante de projeto apresentam relação estatística com o $F N(\rho<0,05)$, fato este já esperado devido as diferenças entre os $P G s$ dos ligantes asfálticos.

$$
\mathrm{FN}=-21361,14+574,66 . P G-2342,97 . T e o r+196,91 . \text { ProporçãoAG - 74,06.Porosidade }
$$

\section{CONCLUSÕES}

Visando compreender a influência do tipo e teor de ligante asfáltico e da granulometria no comportamento à deformação permanente, este artigo avaliou 24 misturas asfálticas através do ensaio uniaxial de carga repetida. Identificou-se que para uma mesma fonte de agregado mineral, ou seja, sem alteração na forma, textura e mineralogia, a mudança no tipo e teor de ligante asfáltico são consideravelmente mais influentes que alterações nas granulometrias das misturas, sendo esse fator importante pois em grande parte dos projetos de revestimentos asfálticos tem-se disponível apenas uma fonte de agregado local. Tais constatações são embasadas pelas fortes correlações encontradas entre os parâmetros reológicos e do teor dos ligantes asfálticos com os FNs das misturas. Isso reforça a necessidade de se utilizar a classificação do ligante asfáltico com base no $P G$, visto sua direta correlação com o comportamento à deformação permanente.

Além disso, as metodologias Bailey e FAD também apresentaram resultados satisfatórios, principalmente o método Bailey com aumento dos FNs das misturas. Ambos os métodos são ferramentas de avaliação da granulometria de forma racional, diferentemente do enquadramento por tentativa e erro em faixas especificadas pela norma do DNIT 031 (2006), que também não se mostrou satisfatório, já que não se constatou um melhor comportamento à deformação permanente das misturas com granulometria Faixa B, mais graúda, em relação às misturas com granulometria da Faixa C.

Entretanto, salienta-se que cada material possui seu campo de aplicação que deve ser avaliado em conjunto com o projeto do pavimento, particularidades e fontes de materiais locais disponíveis e de outro 
tipo de dano como, a fadiga, e assim levar em consideração os aspectos de comportamento discutidos nesta pesquisa.

\section{AGRADECIMENTOS}

Os autores agradecem a Rede Temática de Asfalto/Petrobras pelo suporte a pesquisa e ao CNPq (302677/2015-1) pela bolsa Pq do terceiro autor.

\section{REFERÊNCIAS}

Aashto (2013) M 323 - Standard Specification for Superpave Volumetric Mix Design. American Association of State Highway and Transportation Officials, Washington, D. C.

Aashto (2014) M 332 - Standard Specification for Performance-Grade Asphalt Binder Using Multiple Stress Creep Recovery (MSCR) Test. American Association of State Highway and Transportation Officials, Washington, D. C.

Aashto (2013) T 240 - Standard Method of Test for Effect of Heat and Air on a Moving Film of Asphalt (Rolling Thin-Film Oven Test). American Association of State Highway and Transportation Officials, Washington, D. C.

Aashto (2012) T 313 - Standard Method of Test for Determining the Flexural Stiffness of Asphalt Binder Using the Bending Beam Rheometer (BBR), American Association of State Highway and Transportation Officials, Washington, D. C.

Aashto (2012) T 315 - Standard Method of Test for Determining the Rheological Properties of Asphalt Binder Using a Dynamic Shear Rheometer (DSR), American Association of State Highway and Transportation Officials, Washington, D. C.

Aashto (2013) T 316 - Standard Method of Test for Viscosity Determination of Asphalt Binder Using Rotational Viscometer, American Association of State Highway and Transportation Officials, Washington, D. C.

Aashto (2012) TP 79 - Determining the Dynamic Modulus and Flow Number for Hot Mix Asphalt (HMA) Using the Asphalt Mixture Performance Tester (AMPT). American Association of State Highway and Transportation Officials, Washington, D. C.

ABNT (2016) NBR 1650 - Misturas asfáltica-Resistência à deformação permanente utilizando ensaio uniaxial de carga repetida - Apresentação. Associação Brasileira de Normas Técnicas, Rio de Janeiro.

Adorjányi, K. e P. Füleki (2013) Correlation Between Permanent Deformation-Related Performance Parameters of Asphalt Concrete Mixes and Binders. Central European Journal of Engineering, v. 3, p. 534-540. DOI: 10.2478/s13531-012-0073-6.

Alavi, A. H. M. Ameri; A. H. Gandomi e M. R. Mirzahosseini (2011) Formulation of Flow Number of Asphalt Mixes Usin a Hybrid Computational Method. Construction and Building Materials, v. 25, p. 1338-1355. DOI:10.1016/j.conbuildmat.2010.09.010.

Asphalt Institute (2011) The Bailey Method. Achieving Volumetrics and HMA Compactability. Asphalt Institute. Instructor Bill Pine, Heritage Research Group. Lexington, K Y, January.

ASTM D 2926-04 (2004). Standard Practice Preparation of Bituminous Specimens Using Marshall Apparatus. American Society for Testing and Materials, USA.

Bahia, H. U. (2014) Performance de Asfaltos Modificados com Polímeros. Apresentação em PowerPoint. Anais do $21^{\circ}$ Encontro de Asfalto, Rio de Janeiro, RJ.

Barros, L. M.; L. A. T. Brito e J. Ceratti (2015) Desempenho Quanto à Deformação Permanente de Misturas Asfálticas com Diferentes Ligantes. Anais do XVIII CILA - Congresso Ibero Latino Americano del Asfalto. Bariloche- Patagonia, Argentina.

Bastos, J. B. S.; R. L. Borges; J. B. Soares e L. M. G. Klinsky (2015) Avaliação em Laboratório e em Campo da Deformação Permanente de Pavimentos Asfálticos do Ceará e de São Paulo. transportes, v. 23, n. 3, p. 44-55. DOI: 10.14295/transportes. v23i3.914.

Bastos, J. B. S.; J. B. Soares e L. A. H. Nascimento (2017) Critérios Para os Resultados do Ensaio Uniaxial de Carga Repetida de Misturas Asfálticas em Laboratório a partir do desempenho em Campo. Transportes, v. 25, n. 2, p. 19-40. DOI: 10.14295/transportes.v25i2.1284.

Bastos, J. B. D. (2016) Considerações Sobre a Deformação Permanente de Pavimentos Asfálticos no Dimensionamento Mecanístico-Empírico. Tese (Doutorado em Engenharia de Transportes), Universidade Federal do Ceará, Fortaleza, CE. 200p.

Brown, E.; M. Hainin e Hurley A. C. (2004). NCHRP Report 531 Relationship of Air Voids, Lift Thickness, and Permeability in Hot Mix Asphalt Pavements. Transportation Research Board, National Research Council. Washington, DC. DOI: $10.17226 / 13777$.

Budny, J. (2012) Avaliação do Comportamento Mecânico de Misturas Asfálticas Mornas. Dissertação (Mestrado Engenharia Civil) COPPE, Universidade Federal do Rio de Janeiro, RJ. 137 p.

Centofante, R. (2016) Estudo Laboratorial da Utilização de Material Fresado em Misturas Asfálticas Recicladas a Quente. Dissertação (Mestrado em Engenharia Civil). Centro de Tecnologia, Universidade Federal de Santa Maria, Santa Maria, RS. 152 p.

Corté, J. F.; Y. Brosseaud; J. P. Simoncelli e G. Caroff (1994) Investigation of Rutting of Asphalt Surface Layers: Influence of Binder and Axle Loading Configuration. Transportation Research Record. Asphalt Concrete Mix Materials, n. 1436, p. 28-37.

Cunha, M. B. (2004) Avaliação do Método de Bailey de seleção granulométrica de agregados para misturas asfálticas. Dissertação (Mestrado em Engenharia Civil). Escola de Engenharia de São Carlos, Universidade de São Paulo -EESC, SP. DOI: 10.11606/D.18.2004.tde-19032007-180257.

D'Angelo, J. A. (2009) The Relationship of the MSCR test to rutting. Road Materials and Pavement Design, v. 10, supl.1, p. 61-62. DOI:10.1080/14680629.2009.9690236.

DNER - Departamento Nacional de Estradas de Rodagem (1998) ME 035 Agregados - Determinação da Abrasão Los Angeles: método de ensaio., Rio de Janeiro, RJ. 
DNER- Departamento Nacional de Estradas de Rodagem (1997) ME 054 - Equivalente de Areia. Departamento Nacional de Estradas de Rodagem. Rio de Janeiro, RJ.

DNER- Departamento Nacional de Estradas de Rodagem (1994) ME 078 - Adesividade de Agregado Graúdo e Ligante Betuminoso, Rio de Janeiro, RJ.

DNER - Departamento Nacional de Estradas de Rodagem (1998) ME 081 - Determinação da Absorção e da Densidade de Agregado Graúdo, Rio de Janeiro, RJ.

DNER- Departamento Nacional de Estradas de Rodagem (1994) ME 089 - Agregados - Avaliação da Durabilidade pelo Emprego de Soluções de Sulfato de Sódio ou de Magnésio., Rio de Janeiro, RJ.

DNIT - Departamento Nacional de Infraestrutura de Transportes (2006) ES 031: Pavimentos flexíveis - Concreto asfáltico Especificação de serviço. Rio de Janeiro, RJ.

Domingos, M. D. I. (2011) Caracterização do Comportamento Fluência-Recuperação de Ligantes Asfálticos Modificados Virgens e Envelhecidos. Dissertação (Mestrado em Engenharia de Transportes), Universidade de São Paulo, São Carlos, SP. 299 p

Domingos, M. D. I. e A. L. Faxina (2015) Comportamento de Fluência-Recuperação de Ligantes Asfálticos Modificados com Copolímero SBR e Ácido Polifosfórico. Transportes, v. 23, n. 2, p. 56-64. DOI:10.14295/Transportes.v23i2.800.

Domingos, M. D. I.; A. L. Faxina e L. L. B. Bernucci (2017) Caracterization of the Rutting Potential of Modified Asphalt Binders and Its Correlation With the Mixture's Rut Resistance. Construction and Building Materials, v. 144, p. 207-213. DOI: 10.1016/j.conbuildmat.2017.03.171.

Erkens, S. M. J. G. (2002) Asphalt Concrete Response (ACRe): Determination, Modelling and Prediction. PhS Thesis, Technische Universiteit Delft, Delft, Neherlands.

Ferreira, J. L. S.; J. B. Bastos e J. B. S. Soares (2015) Validação da Metodologia de Faixa de Agregados Dominantes para Avaliação e Especificação da Granulometria de Misturas Asfálticas Densas. XXIX Congresso Nacional de Pesquisa em Transporte da ANPET. Ouro Preto, MG.

Ferreira, J. L. S.; J. B. Soares e J. B. S. Bastos (2016) Método de Seleção Granulométrica com Foco na Resistência à Deformação permanente. Transportes, v. 24, n. 2, p. 46-52. D0I: 10.4237/transportes.v24i2.1129.

Gardete, D. C. (2006) Comparação de Ensaios Laboratoriais para Caracterização de Misturas Betuminosas à Deformação Permanente. Dissertação (Mestrado em Engenharia Rodoviária), Faculdade de Ciências e Tecnologia, Universidade de Coimbra, Coimbra.

Huang. W. e N. Tang (2015) Characterizing SBS Modified Asphalt With Sulfur Using Multiple Stress Creep Recovery Test. Construction and Building Materials, v. 93, p. 514-521. DOI: http://dx.doi.org/10.1016/j.conbuildmat.2015.06.041.

Kim, S. (2006) Identification and Assessment of the Dominant Aggregate Size Range (DASR) of Asphalt Mixture. Dissertation (Doctor of Philosophy), University of Florida, Gainesville. Disponível em: <http://etd.fcla.edu/UF/UFE0013464/kim_s.pdf>. Acesso em: 01 abril 2017.

Kutay, E. M.; A. Jamrah e H. Bayraktaroglu (2017) Analysis of Flow Number Test Data on Asphalt Mixtures from Michigan for use in Pavement Mechanistic-Empirical Software. 96th Annual Meeting TRB Committee. Washington, D. C.

Mahboub, K. e D. N. Little (1988). Improved Asphalt Concrete Design Procedure, Research Report 474- 1F, Texas Transportation Institute. Disponível em: http://tti.tamu.edu/documents/474-1F.pdf (Acesso em: 05/07/2017)

Marques, G. L. O. (2004) Utilização do Módulo de Resiliência como Critério de Dosagem de Mistura Asfáltica; efeito da compactação por impacto e giratória. 461p. Tese (Doutorado em Engenharia Civil) - COPPE/ Universidade Federal do Rio de Janeiro, Rio de Janeiro, RJ.

Melo, J. V. S. (2014) Desenvolvimento e Estudo do Comportamento Reológico e Desempenho Mecânico de Concretos Asfálticos Modificados com Nanocompósitos. 414 p. Tese (Doutorado em Engenharia Civil). Universidade Federal de Santa Catarina, Florianópolis, SC.

Mendes, L. O. e G. L. O. Marques (2012) Avaliação da Influência do Método Bailey no Processo de Dosagem e Desempenho de Misturas Asfálticas. Transportes, v. 20, n. 4, p. 35-43. DOI: 10.4237/transportes.v20i4.574.

Mothé, M. G. (2009) Estudo do Comportamento de Ligantes Asfálticos por Reologia e Análise Térmica. 182 p. Dissertação (Mestrado em Tecnologia de Processos Químicos e Bioquímicos). Universidade Federal do Rio de Janeiro, RJ.

Moura, E. (2010) Estudo de Deformação Permanente em Trilha de Roda de Misturas Asfálticas em Pista e em Laboratório. 299 p. Tese (Doutorado em Engenharia de Transportes). Escola Politécnica da Universidade de São Paulo, São Paulo, SP.

Nascimento, F. A. C; A. C. R, Guimarães e L. A. V. Carneiro (2015) Análise da Influência das Propriedades do Ligante Asfáltico e do Esqueleto Pétreo na Deformação Permanente de Misturas Asfálticas. 34ạ Reunião Anual de Pavimentação. Foz do Iguaçu, PR.

Nascimento, L. A. (2008) Nova abordagem da dosagem de misturas asfálticas densas com uso do compactador giratório e foco na deformação permanente. 204 p. Dissertação (Mestrado em Engenharia Civil). Universidade Federal do Rio de Janeiro, Rio de Janeiro, RJ.

NCHRP (2011) A manual for design of hot mix asphalt with commentary. Cooperative Highway Research Program (NCHRP Report 673). National Cooperative Highway Research Program, Washington. 285 p.

Onofre, F. C. (2012) Avaliação do comportamento mecânico em misturas asfálticas produzidas com ligantes asfálticos modificados por ácido polifosfórico e aditivos poliméricos, enfatizando a resistência à deformação permanente. Dissertação (Mestrado em Engenharia de Transportes). Universidade Federal do Ceará, Fortaleza, CE. 160 p.

Onofre, F. C.; V. T. F. C. Branco; J. B. Soares e A. L. Faxina (2013) Avaliação do Efeito de Ligantes Asfálticos Modificados na Resistência à Deformação Permanente de Misturas Asfálticas Densas. Transportes, v. 21, n. 3, p. 14-21. DOI: 10.4237/transportes.v21i3.685. 
Santagata, E.; O. Baglieri; M. Alam e P. P. Riviera (2015) Evolution of Rutting Properties of Bituminous Binders by Means of Single Shear Creep-Recovery (SSCR) Tests and Correlation with Mixture Performance, $8^{\text {th }}$ RILEM International Symposium Testing and Characterization of Sustainable and Innovative Bituminous Materials, v. 11, p. 745-756. DOI: 10.1007/978-94017-7342-3_60.

Specht, L. P.; A. L. Babadopulos; H. Di Benedetto; C. Sauzeat e J. B. Soares (2017) Application of the Theory of Viscoelasticity to Evalue the Resilient Modulus Test in Asphalt Mixes. Construction and Building Materials, v. 149, p. 648-658. DOI: 10.1016/j.conbuildmat.2017.05.037.

Sumeraj, J. (2016) High Temperature Characteristics of Modified Asphalt Binders. University of Illinois at Urbana-Champaign. Illinois. United States of America. Disponível em: http://www.il-asphalt.org/files/1114/8234/8048/Jacob_Sumeraj_2016_UoI.pdf (Acesso em 03/09/2017)

Valkering, C. P.; D. J. L. Lancon; E. de HILSTER e D. A. Stoker (1990) Rutting Resistence of Asphalt Mixes Containing Nonconventional and Polimer-Modified Binders. Journal of the Association of Asphalt Paving Technologists, v. 59, p. 590-609.

Vavrik, W. R.; G. Huber e W. J. Pine (2002a) Bailey Method for Gradation Selection in HMA Mixture Design, Transportation Research Board: Transportation Research Circular, n. E-C044, Washington, D. C, EUA.

Vavrik, W. R.; W. J. Pine e S. H. Carpenter (2002b) Aggregate Blending for Asphalt Mix Design - Bailey Method. Transportation Research Record, n. 1789, p. 146-153. DOI: 10.3141/1789-16.

Vavrik, W. R.; W. J. Pine; G. A. Huber; S. H. Carpenter e R. Bailey (2001) The Bailey Method of Gradation Evaluation: The Influence of Aggregate Gradation and Packing Characteristics on Voids in Mineral Aggregate. Journal of the Association of Asphalt Paving Technologists, v. 70, p. 132-175.

Wargha Filho, N. (2013) Avaliação da Influência da Redução das Temperaturas de Usinagem e de Compactação no Comportamento Mecânico de Misturas Asfálticas Mornas. 110 p. Dissertação (Mestrado em Engenharia de Transportes). Universidade Federal do Ceará, Fortaleza, CE.

Zhang, J.; A. E. Alvarez; S. I. Lee; A. Torres e L. F. Walubita (2013) Comparison of flow number, dynamic modulus, and repeated load tests for evaluation of HMA permanent deformation. Construction and Building Materials, v. 44, p. 391-398.

DOI:http://dx.doi.org/10.1016/j.conbuildmat.2013.03.013. 